This item was submitted to Loughborough's Research Repository by the author.

Items in Figshare are protected by copyright, with all rights reserved, unless otherwise indicated.

\title{
The effect of multisensory illusions on pain and perceived burning sensations in patients with Burning Mouth Syndrome: A proof-of-concept study
}

\section{PLEASE CITE THE PUBLISHED VERSION}

https://doi.org/10.1111/jop.13065

\section{PUBLISHER}

Wiley

VERSION

AM (Accepted Manuscript)

\section{PUBLISHER STATEMENT}

This is the peer reviewed version of the following article: Nguyen, A.H.P. ... et al. (2020). The effect of multisensory illusions on pain and perceived burning sensations in patients with Burning Mouth Syndrome: A proof-of-concept study. Journal of Oral Pathology and Medicine, 49(6), pgs. 505-513, which has been published in final form at https://doi.org/10.1111/jop.13065. This article may be used for non-commercial purposes in accordance with Wiley Terms and Conditions for Use of Self-Archived Versions

\section{LICENCE}

CC BY-NC-ND 4.0

\section{REPOSITORY RECORD}

Nguyen, AH Phoon, R Balasubramaniam, V Bellan, Roger Newport, and TR Stanton. 2020. "The Effect of Multisensory Illusions on Pain and Perceived Burning Sensations in Patients with Burning Mouth Syndrome: A Proof-of-concept Study". Loughborough University. 
The effect of multisensory illusions on pain and perceived burning sensations in patients with Burning Mouth Syndrome: A proof-of-concept study

Phoon Nguyen A H ${ }^{1}$, Balasubramaniam R ${ }^{1}$, Bellan $\mathrm{V}^{2,4}$, Newport R N $\mathrm{N}^{3}$, Stanton T R ${ }^{4,5}$.

1. The University of Western Australia, UWA Dental School, Australia

2. University of South Australia, Cognitive and Systems Neuroscience Research Hub (CSN-RH), Adelaide, South Australia, Australia

3. School of Sport, Exercise and Health Sciences, Loughborough University, Loughborough, LE11 3TU, United Kingdom

4. University of South Australia, Innovation, Implementation and Clinical Translation (IIMPACT), Adelaide, South Australia, Australia

5. Neuroscience Research Australia, Randwick, New South Wales, Australia 


\section{$\underline{\text { Abstract }}$}

Background: Burning mouth syndrome (BMS) is a chronic pain disorder affecting the oral cavity. Previous work has shown promising analgesic results of bodily illusions in other chronic pain conditions. The aim of this proof-of-concept, pilot study was to investigate whether bodily illusions reduce pain in BMS patients.

Methods: Nine participants diagnosed with BMS underwent bodily illusions using a MIRAGE-mediated reality system. All participants completed 4 conditions and performed standardised movements of the tongue. First, a baseline condition was performed while the tongue was viewed at normal size and colour. Then, three conditions were performed in random order: resizing shrink, colour-based, and incongruent movement illusions. During each condition, participants rated overall pain intensity as well as the intensity of burning pain/sensation on the tongue. Recorded outcome measures were Pain Intensity, Burning Pain Sensation and Intensity, and Embodiment.

Results: There was no difference in overall pain intensity ratings between conditions. However, a significant effect of condition was found for burning pain/sensation of the tongue with the colour condition corresponding to an average pain reduction of $32 \%$ from baseline levels. The colour illusion significantly reduced burning pain compared with baseline ( $\mathrm{MD}=-12.8,95 \% \mathrm{CI}-20.7$ to -4.8$)$ and the shrink illusion condition $(\mathrm{MD}=-$ 11.7, $95 \%$ CI -22.2 to -1.1 ). No other differences for burning pain/sensation were found.

Conclusion: Using visual illusions to change tongue colour resulted in significant reductions in burning sensations in BMS patients. This proof-of-concept study suggests that BMS patients may benefit from bodily illusions, and supports additional research using larger samples and more comprehensive control conditions. 


\section{Introduction}

Burning mouth syndrome (BMS) is defined as "a chronic intraoral burning sensation that has no identifiable cause - either local or systemic condition or disease" (1). The tongue, particularly the tip and anterior two thirds, is most frequently affected, although patients with BMS can also report various qualities of oral mucosal pain, altered taste sensation, and a dry mouth (2,3). Estimated to affect between $0.1 \%$ and $3.9 \%$ of the general population (4), BMS is associated with older age and female sex (2-4), and a wide range of psychological factors (e.g., anxiety, depression) (5-7), although, the cause of burning pain is largely unknown. Many management options have been trialled, including topical or systemic clonazepam, gabapentinoids, as well as other pharmacological and non-pharmacological interventions $(8,9)$. However, to date, few effective treatments are available and management is difficult (8). BMS is usually persistent, with patients reporting significantly reduced quality of life $(10,11)$. It is therefore critical to identify effective interventions.

Emerging research has shown that sensory input from the body and the way that the body is perceived (based upon that sensory input) can have compelling effects on pain. For example, having vision of one's own body can be analgesic (15), and the magnitude of this visually induced analgesia can be influenced by an individual's perception of their body size $(14,16)$. Specifically, using visual illusion to magnify the size of the hand can increase analgesia for experimentally-induced pain, while minimising hand size reduces analgesia (16). Similar effects occur in clinical pain, with a recent meta-analysis finding that bodily illusions show therapeutic promise in numerous pain conditions ((13) For example, bodily illusions that change the perceived size of the knee were analgesic for patients with painful knee osteoarthritis (14). In people with complex regional pain syndrome, minimizing the size of the affected limb (which is typically reported to feel swollen) reduced both pain and swelling, as compared with that typically occurring during standardised movements (17). The latter finding may be particularly relevant to BMS, given that anecdotally, patients with BMS often report that their tongue feels as though it is swollen in the absence of objective swelling. Taken together, the present literature raises the possibility that resizing illusions utilising vision of the participant's own body may also have an analgesic value for BMS.

Visual illusions that alter the colour of the body may hold promise for pain-relief. Colour has long been hypothesized to affect pain $(18,19)$ For example, people with chronic pain choose the colour red to describe their most intense pain (20). Additionally, colour influences perceived pain intensity: a noxious cold stimulus hurts less when preceded by a blue visual cue on the skin, than when preceded by a red visual cue (18). Given associations between red, heat and intense pain, it raises the possibility that burning pain sensations in people with BMS may be relieved by a visual illusion that changes the colour of the tongue to blue. 
Last, body ownership, i.e., the sense that one's body is their own, has also been implicated as a modulator of pain. It has been argued that some bodily illusions cause a sense of disownership in the corresponding real body part and that this might provide a mechanism for analgesia in the real body $(12,21)$. While this evidence is equivocal $(22,23)$, it is important to consider the effects of body ownership (independent of colour and resizing) on pain.

While the relationship is not straightforward, experimental and clinical research have highlighted the possible link between body representation and pain, and underscored the need for further work in this area (13). Given that visual illusions are typically non-invasive and low risk, if effective at reducing pain, they present an attractive pain management option. Therefore, this exploratory proof-of-concept study aimed to determine whether bodily re-sizing, colour-based, and/or incongruent movement (reducing ownership) illusions of the tongue are analgesic in patients with BMS. It was hypothesised that all illusions would be analgesic compared to baseline.

\section{Materials and Methods}

The research was performed in accordance with the Declaration of Helsinki (2008)(24) and with approval from the University of Western Australia (UWA) Human Research Ethics Board (Protocol No.: RA/4/20/4528). All participants provided written, informed consent.

\section{$\underline{\text { Participants }}$}

Nine participants aged over 18 years with normal (or corrected to normal) vision who presented with oral burning (involving, but not limited to the tongue) and a clinical diagnosis of BMS were recruited from patients at the Oral Medicine Clinic, UWA Dental School. Participants were advised that they were invited to participate in a project investigating if visual illusions decrease pain scores in patients with burning mouth syndrome, and that they were asked to take part in this project because they have been diagnosed with burning mouth syndrome. They were also advised: "You will be asked to watch a short video of your own tongue, during which it will appear to change (for example, change size or colour), and then tell us after if this has affected your pain".

Diagnosis of BMS was made using the following criteria (25): i) Oral pain that recurs daily for greater than 2 hours per day and has lasted for more than 3 months; ii) oral pain that is both burning in nature and is felt superficially in the oral mucosa; iii) oral mucosa that is of normal appearance, with normal clinical examination (including sensory testing); iv) presence of symptoms that were not better accounted for by another diagnosis. To exclude secondary causes of oral burning, only people who had undergone blood tests at the time of original BMS diagnosis, (e.g., full blood count, iron studies, Vitamin B12 and serum folate), 
were included. People with cognitive impairment, intellectual disability, a history of neurological disorders, or a diagnosed mental health condition were excluded. Additionally, people without any burning in the tongue on the day of testing were also excluded. No limitations were placed on current treatment regimens being used by participants.

\section{Study design}

A repeated measures pre-post study design was used. Participants underwent one testing session at the Oral Medicine Clinic, UWA Dental School in which they received three experimental conditions, performed in a randomised order. All participants were blinded to condition, and no information about the illusions was provided. One researcher (APN) tested all participants and was not blinded to experimental condition.

\section{Equipment and set-up}

A MIRAGE-mediated-reality system (26) was used to create a virtual distortion mirror. Participants sat directly opposite a 20-inch computer screen displaying live (delay $20 \mathrm{~ms}$ ) digitally manipulated video feed of their own face - as if viewed in a mirror - captured and manipulated via a high-speed camera and computer software (Basler ACa1200-200uc; LabVIEW). The software specifically manipulated either the shape or colour of the face and tongue, or delayed visual feedback so that it no longer matched the participant's movement (see Figure 1).

Testing procedure and experimental conditions:

All participants first underwent a familiarisation phase. During this phase, participants wore a mask over their jaw and mouth, in which a hole was cut out for the tongue to protrude. The mask allowed manipulation of video footage to be focussed on the tongue. With the mask on, participants were asked to view their tongue on the computer screen, and to perform and watch simple movements of their tongue, guided by the researcher's instructions. Light touch and compression were also applied to the tongue by the clinician. This was undertaken to promote participants' embodying the image that they viewed (i.e., so that the tongue that they viewed on their screen felt like it was their own, through congruent vision and touch).

Following this initial familiarisation (20-30 seconds), a 'congruent movement/touch' condition was undertaken whereby a procedure, identical to the familiarisation, was continued for 1 minute. During this time, participants were advised to watch their tongue movement on the screen. This condition served as the baseline ratings for pain and burning sensations. 
Three illusion conditions (Figure 1) were then applied in a randomised order, with each condition lasting approximately 1 minute and with a break of 1-2 minutes between each condition. The shrink illusion condition involved viewing a shrinking/compressing of the tongue that was centred on the area of burning. The researcher provided gentle tactile compression to the dorsal aspect of the anterior third of the tongue; this was accompanied by visual shrinkage of the tongue, changing both width (horizontal plane) and thickness (vertical plane). Participants then performed standardised movements of the tongue (identical to baseline) while it remained shrunken, for approximately 1 minute. In the 'blue tongue' colour illusion condition, the tongue was shown at normal size, but the video seen on screen was colour-inverted such that the tongue appeared blue. Participants performed standardised movements of the tongue for 1 minute while the tongue remained blue. Finally, the incongruent movement condition (designed to reduce embodiment) involved seeing the tongue at normal size/colour but delaying the viewed movement of the tongue by $300 \mathrm{~ms}$, such that what participants saw did not match the movement they performed. Typically, incongruence between the seen and performed movement reduces the sense of ownership over a body part when using mediated reality (27).

\section{Outcome measures:}

During each condition, participants provided pain intensity ratings on a $100 \mathrm{~mm}$ visual analogue scale (VAS) and a Wong Baker faces pain rating scale (28). Burning pain/sensation intensity was also evaluated via a 0$100 \mathrm{~mm}$ VAS ( $0=$ no burning pain/sensation and $100=$ worst burning pain/sensation imaginable). Additionally, a rating of the perceived effect of the tested condition on burning pain/sensation was assessed via a global rating of change scale (options: much worse, a little worse, no different, a little better, much better). Lastly, a customised embodiment questionnaire based on the common principles of illusory embodiment was administered at the end of the session (Table 3) (29).

\section{Statistical analysis:}

Statistical analyses were performed using IBM SPSS 22.0 or RStudio (version 1.2.1335; RStudio Team, 2018). Data were assessed for normality using visual inspection and Shapiro-Wilk statistic. If the normality assumption was not met, non-parametric analyses were used. Primary analyses were limited to planned comparisons between each of the three experimental conditions and the baseline condition, using a HolmBonferroni correction for multiple comparisons (30). Exploratory analyses were undertaken between the experimental conditions, with no correction for multiple comparisons.

Pain intensity (VAS) ratings were non-normally distributed so the Related Samples Wilcoxon Signed Rank test was completed. Additionally, because the Wong Baker Faces Scale is an ordinal scale, the same nonparametric test (and comparisons) were undertaken. Burning pain intensity ratings were normally distributed, 
so paired sample t-tests were completed. Due to large inter-individual variability, the burning pain intensity ratings were also analysed using a linear mixed model analysis, with participant as a random factor. Burning pain data used in the linear mixed model analysis were inspected and analysed by using custom-made scripts in RStudio version 1.2.1335 (RStudio Team, 2018) for Windows. The lme4 package was used for linear mixed-effects models (31). Different packages from the Tidyverse collection were used to explore and plot the data (32). Akaike Information Criterion [AIC; (33)], Bayesian Information Criterion [BIC; (34)], and loglikelihood were used to assess the fit of the linear mixed models Global ratings of change for burning pain were summarised via frequencies.

\section{Results}

Twelve patients were screened for study inclusion. One patient was excluded due to macular degeneration with vision loss, and 2 patients withdrew, leaving a total of nine participants recruited to the study (Table 1). The mean age of the participants was 67.3 years (SD 12.2) and their mean Wong Baker score at baseline was $5.11(\mathrm{SD} 1.96)$. 


\section{Effect of condition on overall pain intensity:}

There was no effect of condition on pain intensity as measured by a $100 \mathrm{~mm}$ VAS. Specifically, planned comparisons in the primary analysis showed that there was no difference between baseline and the shrink illusion condition $(\mathrm{p}=0.89)$, the colour condition $(\mathrm{p}=0.36)$, or the incongruent movement condition $(\mathrm{p}=0.26)$ (Table 2). Similarly, there were no differences for the Wong Baker Faces scores between baseline and the shrink illusion condition $(\mathrm{p}=0.85)$, the colour condition $(\mathrm{p}=0.10)$, or the loss of embodiment condition $(\mathrm{p}=0.66)$.

Exploratory analyses showed that the pain intensity ratings did not differ between the shrink illusion and incongruent movement condition $(\mathrm{p}=0.49)$ or the colour condition $(\mathrm{p}=0.19)$, although comparison between the colour and incongruent movement condition approached significance $(\mathrm{p}=0.066)$. Similarly, Wong Baker Faces scores did not differ between the shrink illusion and incongruent movement condition $(\mathrm{p}=0.414)$, or the colour and incongruent movement condition $(\mathrm{p}=0.10)$, although comparison between the colour and shrink illusion condition approached significance $(\mathrm{p}=0.059)$.

\section{Effect of condition on burning pain intensity:}

A significant effect of condition was found for burning pain VAS ratings (Table 2). Specifically, planned comparisons in the primary analysis showed that the colour condition significantly reduced burning pain compared to baseline $\left(t_{1,8}=3.7, p=0.006\right.$; Figure $\left.2 \mathrm{a}\right)$, but that there were no differences between baseline and the shrink illusion condition $\left(\mathrm{t}_{1,8}=0.26, \mathrm{p}=0.80\right.$; Figure $\left.2 \mathrm{~b}\right)$ or the incongruent movement condition $\left(\mathrm{t}_{1,8}=1.16\right.$, $\mathrm{p}=0.28$; Figure $2 \mathrm{c}$ ). These findings were confirmed by the linear mixed model analysis, which showed that even when considering the participant as a random effect, only the Colour condition differed from baseline with an average reduction of $12 \mathrm{~mm}$ on a $100-\mathrm{mm} \operatorname{VAS}\left(\mathrm{t}_{1,27}=-2.9, \mathrm{p}=0.007\right)$. This corresponds to an average pain reduction of $32 \%$ from baseline levels.

Exploratory analyses showed that for burning pain intensity VAS ratings, the Colour condition also significantly reduced burning pain compared with the shrink illusion condition $\left(\mathrm{t}_{1,8}=2.6, \mathrm{p}=0.034 ; \mathrm{MD}=-11.7\right.$, 95\% CI -22.2 to -1.1; Figure 3, but did not differ from the incongruent movement condition $\left(\mathrm{t}_{1,8}=1.6, \mathrm{p}=0.16\right.$; $\mathrm{MD}=-6.1,95 \% \mathrm{CI}-15.1$ to 2.9$)$. The incongruent movement condition did not differ from the shrink illusion $\left(\mathrm{t}_{1,8}=1.0, \mathrm{p}=0.35 ; \mathrm{MD}=-5.6,95 \%\right.$ CI -7.3 to 18.4$)$.

The primary effects of condition on burning pain seen were largely supported by global ratings of change scores, the latter of which highlight inter-individual variability. In the resizing condition, $67 \%$ reported no difference in burning pain, with 33\% reporting they were a little better. In the incongruent movement condition (via incongruent movement), $75 \%$ reported no difference in burning pain, and $25 \%$ reported they were a little 
better. Lastly, in the colour condition, $50 \%$ of participants reported feeling a little better in the colour condition, compared to only $25 \%$ and $33 \%$ in the incongruent movement and resizing illusions respectively. All other ratings were reported as feeling no different.

\section{Manipulation check: embodiment ratings in illusion conditions}

Overall, the incongruent movement illusion appeared successful at reducing participants' sense that the viewed tongue was their own (Table 3). In the incongruent movement condition, the average rating to the item "It felt like the tongue was my tongue" was 1.5 points, whereas in the re-sizing condition, the average rating was 3 points (strongly agree) and for the colour condition was 2 points. Similarly, the item "I felt like I was looking at my own tongue" was only 1.25 points for the incongruent movementcondition, compared with 3 for the resizing condition and 2.5 for the colour condition.

\section{Discussion}

This study found preliminary evidence that body illusions could be analgesic in patients suffering from BMS for the duration of the study intervention. Specifically, the colour illusion, in which the mirrored view was colour-inverted, and the tongue appeared blue, resulted in a significant reduction in perceived oral burning. The experimental conditions of shrinking and of incongruent movement did not have an effect on pain scores, contrary to our hypotheses.

Numerous studies have evaluated the use of visual body illusions in clinical pain conditions, in an effort to induce analgesia. This is the first study, to the authors' knowledge, of its use in BMS. While the nature of this relationship is not clear, there exists an ever-growing body of evidence for the presence of a complex relationship between pain perception and disruption of bodily perceptions of the painful area $(14,35,36)$, and our study's findings support this relationship. Neuroimaging studies support such body-related visual analgesia, showing an activation of the inhibitory GABAergic interneurons in the somatosensory areas in response to the vision of the own body (39). Preliminary neuroimaging findings suggest that visually induced analgesia involves separate mechanisms than non-specific effects of treatment (i.e., placebo effects) (39). While such analgesia does not involve an overall reduction of the cortical response (activation in response to nociceptive input), rather, it appears that analgesia is consequent to the interplay between the brain's nociceptive network and the posterior parietal network for visual body perception, which results in modulation of the experience of pain (39).

\section{Resizing Illusion}


The shrink illusion did not influence pain. The relationship between bodily resizing illusions and pain relief is not straightforward. Past work in people with complex regional pain syndrome show that distortions in body perception typically involve the limb feeling larger than it truly is, with visual illusions that make the limb look/feel smaller reducing pain (35). Such findings could predict pain reductions with shrinking illusions in BMS given the common perception that their tongue is larger or more swollen than it actually is. However, other research in osteoarthritis of the knee and hand $(14,26)$ have shown greater benefits for stretching/enlarging than shrinking illusions, perhaps because enlargement reduces the discrepancy between the size of the seen and felt (to be swollen) body part. Different re-sizing illusions tailored to individual variation in perceived tongue size should be more fully explored in future studies before discounting their potential analgesic effect.

\section{Colour Illusion}

Our current findings of a blue coloured tongue (to contrast with the red colour of the 'burning' tongue) reducing oral burning pain are supported by previous work showing influences of colour on pain $(18,19)$. One hypothesis underlying effects of colour on pain might be that colour induces unconscious associations that interconnect with body representation and protection (e.g., as we typically learn that red equates to 'hot' and potentially 'dangerous' and blue equates to 'cold'). A reddened arm significantly decreased the heat pain threshold compared with normal and bluish skin, and only when colour was seen on the arm itself (20). Moreover, people exposed to blue light prior to venous cannulation had reduced frequency and severity of pain (vs white or red light) Last, synaesthetes (i.e., people who have multiple sensory experiences with stimulation of one sensory pathway), provide evidence that there is potential for automatic cross-modal links between words and colours. This opens up the possibility that colours might automatically activate semantics or metonyms associated with those colours (e.g; between red, fire and pain or between blue, cold and numbness) (40).

\section{Incongruent Movement}

The incongruent movement condition had no effect on any of the pain measures. The current study was therefore unable to add clarity to the equivocal evidence for modulation of pain through incongruent movement and/or disownership. However, the exploratory analysis revealed the potential for significant effects, suggesting that future work might be warranted using methodological improvements to enhance the loss of ownership and agency (e.g., ensuring viewed tongue movement is optimally out of phase with actual tongue movement).

\section{Study limitations and future directions}

One limitation of this study was the small sample size, although an initial proof of concept study with low participant numbers is not unusual $(14,21,36,37,41)$. Additionally, the researcher was un-blinded which 
increases potential bias. However, that we hypothesised all conditions would be analgesic (versus baseline), but only one (colour) showed significant analgesia, this supports against an over-arching biased induced by the researcher or by participant expectations. Future double-blinded studies with larger participant numbers would enable robust evaluation with further statistical analysis, potentially considering the influence of individual participant characteristics to any effect seen.

The present results warrant replication and extension in a larger sample, to ascertain whether oral burning can be reduced in a clinically meaningful way through the use of illusions. The present evaluated illusions were short-lasting and applied only once. While the average pain reduction was $12 \mathrm{~mm}$ on a $100 \mathrm{~mm}$ scale, this was only an immediate effect. As such, it is relevant to determine whether sustained and/or repeated illusions might result in additional benefit, either via larger reductions in pain or sustained reductions in pain following visual illusions (14). More comprehensive assessment on clinical outcomes would also facilitate the needed transition of research-based technology into clinical friendly versions, or for use in the home, for example, using webcams or tablets.

\section{Conclusions}

The effect of bodily illusions in pain is an emerging area of research, with potentially promising results. To the authors' knowledge, this is the first study exploring the use of body illusions in orofacial pain. This pilot study found a statistically significant effect of a colour illusion on reducing oral burning in BMS patients. Specifically, colour-inversion of the tongue from predominantly red to blue reduced reported pain intensity by $32 \%$. Incongruent movement and resizing illusions had no statistically significant effect on pain, but may require further exploration given the relatively brief evaluation undertaken (e.g., shrink illusions only). While promising, the preliminary nature of this research underscores the need to undertake larger, better controlled investigations in BMS, orofacial pain and, more broadly, across a range of chronic pain conditions.

\section{Funding sources}

TRS is supported by a National Health \& Medical Research Council Career Development Fellowship (ID1141735). The funders had no role in study design, data collection and analyses, decision to publish, or preparation of the manuscript.

\section{Conflict of Interest}

TRS received travel and accommodation support from Eli Lilly Ltd for speaking engagements (2014; unrelated to the present topic). RN is the creator of the MIRAGE mediated-reality systems. The other authors have no conflicts to declare. 


\section{References}

1. IASP (2016). IASP orofacial pain fact sheet. Burning mouth syndome. [Internet]. Available from: https://s3 .amazonaws.com/rdcmsiasp/files/production/public/Content/ContentFolders/GlobalYearAgainstPain2/20132014OrofacialPain/ FactSheets/Burning_Mouth_Syndrome_2016.pdf

2. Grushka M, Epstein JB, Gorsky M. Burning mouth syndrome. Am Fam Physician. 2002 Feb 15;65(4):615-20.

3. Hakeberg M, Berggren U, Hägglin C, Ahlqwist M. Reported burning mouth symptoms among middleaged and elderly women. Eur J Oral Sci. 1997;105(6):539-43.

4. Kohorst JJ, Bruce AJ, Torgerson RR, Schenck LA, Davis MDP. A Population-Based Study of the Incidence of Burning Mouth Syndrome. Mayo Clin Proc. 2014 Nov 1;89(11):1545-52. 
5. van der Ploeg HM, van der Wal N, Eijkman MA, van der Waal I. Psychological aspects of patients with burning mouth syndrome. Oral Surg Oral Med Oral Pathol. 1987 Jun;63(6):664-8.

6. Jääskeläinen SK, Woda A. Burning mouth syndrome. Cephalalgia. 2017 Jun;37(7):627-47.

7. Maina G, Albert U, Gandolfo S, Vitalucci A, Bogetto F. Personality Disorders in Patients with Burning Mouth Syndrome. J Personal Disord. 2005 Feb;19(1):84-93.

8. McMillan R, Forssell H, Buchanan JA, Glenny A-M, Weldon JC, Zakrzewska JM. Interventions for treating burning mouth syndrome. Cochrane Database Syst Rev [Internet]. 2016 [cited 2019 Jun 2];(11). Available from: https://www.cochranelibrary.com/cdsr/doi/10.1002/14651858.CD002779.pub3/abstract

9. Amos K, Yeoh S-C, Farah CS. Combined topical and systemic clonazepam therapy for the management of burning mouth syndrome: a retrospective pilot study. J Orofac Pain. 2011;25(2):12530 .

10. Fukushima Y, Kitamura T, Ikami E, Yumoto M, Sano Y, Sato T, et al. A case of burning mouth syndrome leading to suicide 10 days after self-cutting of tongue. Psychogeriatr Off J Jpn Psychogeriatr Soc. 2019 Apr 7;

11. Pinto A, Sollecito TP, DeRossi SS. Burning mouth syndrome. A retrospective analysis of clinical characteristics and treatment outcomes. N Y State Dent J. 2003 Mar;69(3):18-24.

12. Serino A, Alsmith A, Costantini M, Mandrigin A, Tajadura-Jimenez A, Lopez C. Bodily ownership and self-location: components of bodily self-consciousness. Conscious Cogn. 2013 Dec;22(4):123952.

13. Boesch E, Bellan V, Moseley GL, Stanton TR. The effect of bodily illusions on clinical pain: a systematic review and meta-analysis. Pain. 2016 Mar;157(3):516-29.

14. Stanton TR, Gilpin HR, Edwards L, Moseley GL, Newport R. Illusory resizing of the painful knee is analgesic in symptomatic knee osteoarthritis. PeerJ. 2018;6:e5206.

15. Longo MR, Betti V, Aglioti SM, Haggard P. Visually Induced Analgesia: Seeing the Body Reduces Pain. J Neurosci. 2009 Sep 30;29(39):12125-30.

16. Mancini F, Longo MR, Kammers MPM, Haggard P. Visual Distortion of Body Size Modulates Pain Perception. Psychol Sci. 2011 Mar;22(3):325-30.

17. Moseley GL, Parsons TJ, Spence C. Visual distortion of a limb modulates the pain and swelling evoked by movement. Curr Biol CB. 2008 Nov 25;18(22):R1047-1048.

18. Moseley GL, Arntz A. The context of a noxious stimulus affects the pain it evokes. PAIN®. 2007 Dec 15;133(1):64-71.

19. Wiercioch-Kuzianik K, Bąbel P. Color Hurts. The Effect of Color on Pain Perception. Pain Med Malden Mass. 2019 01;20(10):1955-62.

20. Martini M, Pérez Marcos D, Sanchez-Vives MV. What Color is My Arm? Changes in Skin Color of an Embodied Virtual Arm Modulates Pain Threshold. Front Hum Neurosci [Internet]. 2013 [cited 2019 May 28];7. Available from: https://www.frontiersin.org/articles/10.3389/fnhum.2013.00438/full

21. McCabe CS. A controlled pilot study of the utility of mirror visual feedback in the treatment of complex regional pain syndrome (type 1). Rheumatology. 2002 Jan 1;42(1):97-101. 
22. Mohan R, Jensen KB, Petkova VI, Dey A, Barnsley N, Ingvar M, et al. No pain relief with the rubber hand illusion. PloS One. 2012;7(12):e52400.

23. Bauer A, Hagenburger J, Plank T, Busch V, Greenlee MW. Mechanical Pain Thresholds and the Rubber Hand Illusion. Front Psychol. 2018;9:712.

24. World Medical Association Inc. Declaration of Helsinki. Available from: https://www.wma.net/wpcontent/uploads/2016/11/DoH-Oct2008.pdf

25. Headache Classification Committee of the International Headache Society (IHS) The International Classification of Headache Disorders, 3rd edition. Cephalalgia. 2018 Jan;38(1):1-211.

26. Preston C, Newport R. Analgesic effects of multisensory illusions in osteoarthritis. Rheumatology. 2011 Dec 1;50(12):2314-5.

27. Ratcliffe N, Newport R. The Effect of Visual, Spatial and Temporal Manipulations on Embodiment and Action. Front Hum Neurosci. 2017 May 4;11:227.

28. Stuppy DJ. The Faces Pain Scale: reliability and validity with mature adults. Appl Nurs Res ANR. 1998 May;11(2):84-9.

29. Botvinick M, Cohen J. Rubber hands 'feel' touch that eyes see. Nature. 1998 Feb;391(6669):756.

30. S H. A simple sequentially rejective multiple test procedure S. Holm. Scandinavian Journal of Statistics. J Stat. 1979;6(2):65--70.

31. Bates D, Mächler M, Bolker B, Walker S. Fitting Linear Mixed-Effects Models Using Ime4. J Stat Softw [Internet]. 2015 [cited 2020 May 7];67(1). Available from: http://www.jstatsoft.org/v67/i01/

32. Wickham H, Averick M, Bryan J, Chang W, McGowan L, François R, et al. Welcome to the Tidyverse. J Open Source Softw. 2019 Nov 21;4(43):1686.

33. Akaike H. A new look at the statistical model identification. IEEE Trans Autom Control. 1974 Dec;19(6):716-23.

34. Schwarz G. Estimating the Dimension of a Model. Ann Stat. 1978 Mar;6(2):461-4.

35. Moseley GL. Distorted body image in complex regional pain syndrome. Neurology. 2005 Sep $13 ; 65(5): 773$.

36. Gilpin H, Moseley L, Stanton T, Newport R. Evidence for distorted mental representation of the hand in osteoarthritis. Rheumatol Oxf Engl. 2014 Sep 22;54.

37. Longo MR, Iannetti GD, Mancini F, Driver J, Haggard P. Linking Pain and the Body: Neural Correlates of Visually Induced Analgesia. J Neurosci. 2012 Feb 22;32(8):2601-7.

38. Cardini F, Longo MR, Haggard P. Vision of the Body Modulates Somatosensory Intracortical Inhibition. Cereb Cortex. 2011 Sep 1;21(9):2014-22.

39. Zanini A, Montalti M, Caola B, Leadbetter A, Martini M. Pain during illusory own arm movement: A study in immersive virtual reality. EMJ. 2017 Mar 1;2(2):90-7.

40. Harvey JP. Sensory perception: lessons from synesthesia: using synesthesia to inform the understanding of sensory perception. Yale J Biol Med. 2013 Jun;86(2):203-16. 
41. Schmalzl L, Ragnö C, Ehrsson HH. An Alternative to Traditional Mirror Therapy: Illusory Touch Can Reduce Phantom Pain When Illusory Movement Does Not. Clin J Pain. 2013 Oct;29(10):e10-8.

\section{Figure Captions}

Figure 1: Pictorial representation of the experimental set-up. Top, showing the arrangement of participant, camera and monitor and the participant's view of the monitor 'mirror' in the Baseline condition. Bottom, showing the Colour-inverted, Shrink and Incongruent Movement conditions from left to right. Note that for the Shrink condition, only the tongue region has been reduced in size, leaving the rest of the face untouched.

Figure 2: Burning pain intensity ratings during experimental conditions compared with baseline ratings. A) Shrinking illusions versus baseline; B) Colour illusion versus baseline; C) Incongruent movement illusion versus baseline. Each line represents an individual participant's ratings, with the solid black line representing the average change in burning pain across the sample.

Figure 3: Exploratory analysis comparing burning pain intensity ratings during the Colour illusion to the shrinking illusion condition. Each line represents an individual participant's ratings, with the solid black line representing the average change in burning pain across the sample.

\begin{tabular}{|c|c|c|c|c|c|}
\hline $\begin{array}{l}\text { Participant } \\
\text { Number }\end{array}$ & Age & Sex & Medications & $\begin{array}{l}\text { Duration } \\
\text { of BMS } \\
\text { (Months } \\
\text { ) }\end{array}$ & $\begin{array}{l}\text { Primary Symptoms } \\
\text { and Location }\end{array}$ \\
\hline $\mathrm{P} 1$ & 60 & $\mathrm{~F}$ & $\begin{array}{l}\text { pantoprazole, topical } \\
\text { clonazepam }\end{array}$ & 27 & Tongue \\
\hline $\mathrm{P} 2$ & 56 & $\mathrm{~F}$ & $\begin{array}{l}\text { diltiazem, atorvastatin, } \\
\text { esomeprazole }\end{array}$ & 36 & Tongue \\
\hline P3 & 70 & M & $\begin{array}{l}\text { perindopril, sertraline, } \\
\text { paracetamol }\end{array}$ & 18 & $\begin{array}{l}\text { Tongue, buccal } \\
\text { gingiva, hard palate }\end{array}$ \\
\hline P4 & 91 & $\mathrm{~F}$ & $\begin{array}{l}\text { indomethacin } \\
\text { pantoprazole }\end{array}$ & 28 & Tongue, hard palate \\
\hline P5 & 62 & $\mathrm{~F}$ & $\begin{array}{l}\text { atorvastatin } \\
\text { candesartan, } \\
\text { clonazepam }\end{array}$ & 14 & Tongue \\
\hline
\end{tabular}




\begin{tabular}{|l|l|l|l|l|l|}
\hline P6 & 56 & $\mathrm{~F}$ & $\begin{array}{l}\text { aspirin, tramadol, topical } \\
\text { clonazepam }\end{array}$ & 10 & Tongue \\
\hline P7 & 83 & $\mathrm{~F}$ & $\begin{array}{l}\text { duloxetine, pregabalin, } \\
\text { thyroxine, aspirin }\end{array}$ & 44 & Tongue, hard palate \\
\hline P8 & 66 & $\mathrm{~F}$ & $\begin{array}{l}\text { tacrolimus, prednisolone, } \\
\text { abatacept }\end{array}$ & Tongue \\
\hline P9 & 62 & $\mathrm{M}$ & $\begin{array}{l}\text { atorvastatin, mirtazapine, } \\
\text { temazepam, amitriptyline, } \\
\text { paracetamol }\end{array}$ & Tongue \\
\hline
\end{tabular}

Table 1: Patient Demographics

\begin{tabular}{|c|c|c|}
\hline Comparison & Mean difference & $95 \%$ CI of the difference \\
\hline \multicolumn{3}{|c|}{ Primary: Pain intensity $100 \mathrm{~mm}$ VAS } \\
\hline Shrink illusion vs Baseline & 0.56 & -9.3 to 10.4 \\
\hline Colour illusion vs Baseline & -3.9 & -12.4 to 4.7 \\
\hline $\begin{array}{l}\text { Incongruent movement vs } \\
\text { Baseline }\end{array}$ & 3.3 & -3.3 to 10.0 \\
\hline \multicolumn{3}{|c|}{ Primary: Wong Baker Faces Pain Scale } \\
\hline Shrink illusion vs Baseline & 0.11 & -0.94 to 1.2 \\
\hline Colour illusion vs Baseline & 0.56 & -1.2 to 0.12 \\
\hline $\begin{array}{l}\text { Incongruent movement vs } \\
\text { Baseline }\end{array}$ & 0.11 & -0.7 to 0.5 \\
\hline \multicolumn{3}{|c|}{ Primary: Burning pain intensity $100 \mathrm{~mm} \mathrm{VAS}$} \\
\hline Shrink illusion vs Baseline & -1.11 & -10.9 to 8.6 \\
\hline Colour illusion vs Baseline & -12.8 & -20.7 to -4.8 \\
\hline $\begin{array}{l}\text { Incongruent movement vs } \\
\text { Baseline }\end{array}$ & -6.7 & -20.0 to 6.6 \\
\hline \multicolumn{3}{|c|}{ Exploratory: Burning pain intensity $100 \mathrm{~mm}$ VAS } \\
\hline Colour vs Shrink illusion & -11.7 & -18.4 to -1.1 \\
\hline $\begin{array}{l}\text { Colour vs Incongruent } \\
\text { movement }\end{array}$ & -6.1 & -22.2 to 2.9 \\
\hline $\begin{array}{lll}\text { Incongruent movement vs } \\
\text { Shrink }\end{array}$ & -5.6 & -18.4 to 7.3 \\
\hline
\end{tabular}

Table 2. Mean differences and 95\% confidence intervals for pain outcomes. 


\begin{tabular}{|c|c|c|c|c|c|c|c|c|c|c|c|}
\hline Participants & $\begin{array}{l}\text { I felt as } \\
\text { if I was } \\
\text { looking } \\
\text { at my } \\
\text { own } \\
\text { tongue }\end{array}$ & $\begin{array}{l}\text { I felt as } \\
\text { if the } \\
\text { tongue } \\
\text { was } \\
\text { part of } \\
\text { my } \\
\text { body }\end{array}$ & $\begin{array}{l}\text { It seemed as } \\
\text { if I were } \\
\text { sensing the } \\
\text { movement } \\
\text { of my } \\
\text { tongue in } \\
\text { the location } \\
\text { where the } \\
\text { video } \\
\text { moved }\end{array}$ & $\begin{array}{l}\text { I felt as } \\
\text { if the } \\
\text { tongue } \\
\text { was my } \\
\text { tongue }\end{array}$ & $\begin{array}{l}\text { It } \\
\text { seems } \\
\text { as if I } \\
\text { had } \\
\text { more } \\
\text { than } 1 \\
\text { tongue }\end{array}$ & $\begin{array}{l}\text { The } \\
\text { tongue } \\
\text { moved } \\
\text { just like } \\
\text { I wanted } \\
\text { it to, as } \\
\text { if it was } \\
\text { obeying } \\
\text { my will }\end{array}$ & $\begin{array}{l}\text { I felt as if I } \\
\text { was } \\
\text { controlling } \\
\text { the } \\
\text { movements } \\
\text { of the } \\
\text { tongue }\end{array}$ & $\begin{array}{l}\text { I felt as if I } \\
\text { was } \\
\text { causing } \\
\text { the } \\
\text { movement } \\
\text { I saw }\end{array}$ & $\begin{array}{l}\text { Whenever } \\
\text { I moved } \\
\text { my } \\
\text { tongue I } \\
\text { expected } \\
\text { the } \\
\text { tongue to } \\
\text { move in } \\
\text { the same } \\
\text { way }\end{array}$ & $\begin{array}{l}\text { I felt as if } \\
\text { the tongue } \\
\text { was } \\
\text { controlling } \\
\text { my will }\end{array}$ & $\begin{array}{l}\text { It } \\
\text { seemed } \\
\text { as if the } \\
\text { tongue } \\
\text { had a } \\
\text { will of its } \\
\text { own }\end{array}$ \\
\hline \multicolumn{12}{|c|}{ Embodiment scores for participants completing the re-sizing illusion last } \\
\hline \multicolumn{12}{|c|}{ Embodiment scores for participants completing the colour illusion last } \\
\hline $\mathrm{P} 2$ & 2 & 1 & 0 & 1 & -3 & 3 & 2 & 2 & 3 & 1 & -1 \\
\hline $\mathrm{P} 3$ & 3 & 3 & -3 & 3 & -3 & 3 & 3 & 3 & 3 & -3 & -3 \\
\hline \multicolumn{12}{|c|}{ Embodiment scores for participants completing the loss of embodiment illusion last } \\
\hline P3 & 0 & 0 & 0 & 0 & -1 & 1 & 0 & 0 & 0 & 0 & -1 \\
\hline $\mathrm{P} 4$ & 1 & 1 & 1 & 1 & 1 & 1 & 1 & 1 & 2 & 0 & 0 \\
\hline P5 & 2 & 2 & 2 & 3 & -3 & 1 & 3 & 3 & 3 & 3 & 3 \\
\hline P9 & 2 & 2 & 2 & 2 & -1 & 0 & 0 & 1 & 0 & -1 & 0 \\
\hline
\end{tabular}


Table 3. Embodiment Questionnaire; adapted from the Rubber Hand illusion questionnaire (Botvinick and Cohen (29). Scale from -3 (Strongly disagree) to 3 (Strongly agree). 